TIMELINE

\title{
The early history of B cells
}

\section{Max D. Cooper}

Abstract | The separate development of functionally intertwined lineages of lymphocytes known as B cells and T cells is now recognized as a fundamental organizing principle of the adaptive immune system in all vertebrates. Immunologists strive to define the different sublineages of the clonally diverse $B$ cells and T cells, how they interact with each other and how they interact with innate lymphoid cells and other elements of the innate immune system to counter infections, cancer and the development of autoimmune and inflammatory diseases. On the 50th anniversary of the recognition of B cells as a discrete cell lineage, this Timeline article recounts some of the milestones marking the development of the concept that B cells are a functionally and developmentally distinct arm of the adaptive immune system.

The first clear functional indication of the existence of cells that we now know as B cells came in 1890 with the discovery by Emil von Behring and Shibasaburo Kitasato ${ }^{1}$ of the importance of circulating antitoxins in immunity to diphtheria and tetanus. Paul Ehrlich proposed that the producers of the antitoxins were cells with pre-formed antibody receptors ${ }^{2}$. He envisioned that an immune cell bearing many different antibody receptors would somehow be stimulated by binding an antigen to produce and to release more of the receptor type complementary to that antigen. The elaboration of this idea by Felix Haurowitz ${ }^{3}$ and others led to the 'antigen-template' or 'instructional' model of antibody production.

The elucidation of the physical nature of antibodies as a first step to understanding the antigen-antibody relationship began in the 1930s, when the use of Tiselius' electrophoresis method to separate serum proteins demonstrated that antibodies are $\gamma$-globulins ${ }^{4}$. Identification of the cellular source of antibodies came almost a decade later in 1948, when plasma cell development was noted to correlate with antibody responses following immunization ${ }^{5}$. Antibody production by plasma cells was subsequently verified using immunofluorescence microscopy ${ }^{6}$.

With our current wealth of information about $B$ cells and $T$ cells as the central characters of the adaptive immune system, it is difficult to imagine that the immunological functions of lymphocytes were unknown before the 1960s, when a series of convergent findings in birds, mammals and immunodeficient patients led to the experimental delineation of distinctive B cell and T cell lineages in 1965 (REF. 7). This Timeline article outlines some of the early discoveries that led to the recognition of $\mathrm{B}$ cells as a separate lymphocyte lineage (FIG. 1) and the early studies investigating the implications of this partition between B cells and T cells. The article proceeds to recount how the genetic basis for B cell receptor (BCR) diversification was solved during the dawn of molecular immunology, before concluding with a brief consideration of the ancient evolutionary origin of the $\mathrm{B}$ cell and $\mathrm{T}$ cell lineages.

\section{Cellular versus humoral immunity}

In the 1940s, Merrill Chase and Karl Landsteiner ${ }^{8,9}$, who discovered human blood groups and the hapten specificity of antibodies, carried out adoptive transfer experiments in guinea pigs to show that contact sensitivity to simple chemical compounds or delayedtype hypersensitivity to tuberculin could be transferred to naive recipients by living cells in peritoneal exudate, but not by dead cells or by serum from immunized donors. Their results indicated that specific adaptive immune responses could be categorized as either cell-mediated immunity or humoral antibody-mediated immunity; however, the potential role of antibodies in the specificity of cell-mediated immunity continued to be hotly debated over the next several years. Parenthetically, the idea of innate immunity being mediated by phagocytes had been championed much earlier by Ilya Mechnikov ${ }^{10}$.

Studies of hereditary defects of immunity in humans also provided insight into the humoral versus cellular components of an immune response. The first such immunodeficiency disease was recognized by Ogden Bruton ${ }^{11}$, who observed in 1952 the absence of serum $\gamma$-globulins in a young boy suffering from multiple bacterial infections. Bruton interpreted this finding as an indication of the boy's inability to make antibodies and he treated the patient with $\gamma$-globulins from healthy donors to provide protection from subsequent infections. In other boys with congenital agammaglobulinaemia (now known as X-linked agammaglobulinaemia), Robert Good and Richard Varco $^{12}$ in 1955 described the absence of germinal centres and plasma cells as cellular correlates of the antibody deficiency and noted the presence of essentially normal numbers of lymphocytes, intact cell-mediated immunity and the ability to control viral and fungal infections.

With the exception of Mechnikov's studies in starfish, these studies were all carried out in mammals. Contemporaneous studies in birds offered unanticipated insight into immune system development. Bruce Glick removed the bursa of Fabricius, a hindgut lymphoid organ, from newly hatched chicks to test its role in behavioural development. The bursectomized birds developed normally but, when birds left over from his experiment were used in a classroom demonstration of antibody production, some of them failed to make antibodies. In follow-up studies, early bursectomy was consistently shown to prevent the development of normal antibody responses. The report of these findings was rejected by a mainstream journal because it was not considered to be of general interest and its publication in Poultry Science in 1956 (REF. 13) was unnoticed at the time by immunologists. Thus, although all of these observations were indicative of a distinction between cellular and humoral immunity, an integrated interpretation of the results was obscured at the time by their derivation from experiments in disparate species.

\section{Defining antibody structure and diversity}

The issues that fascinated most immunologists in the mid-twentieth century were the structural nature of antibodies and the basis for their antigen-binding specificities. The diversity of antibodies complicated their biochemical analysis, but the recognition that multiple myelomas are malignant clones of plasma cells offered a convenient source of homogeneous antibodies for experimentation. A major breakthrough was provided by Gerald Edelman's and Rodney Porter's studies $^{14,15}$ in the late 1950 s that revealed the four-chain composition of antibodies, formed by paired heavy chains and paired 


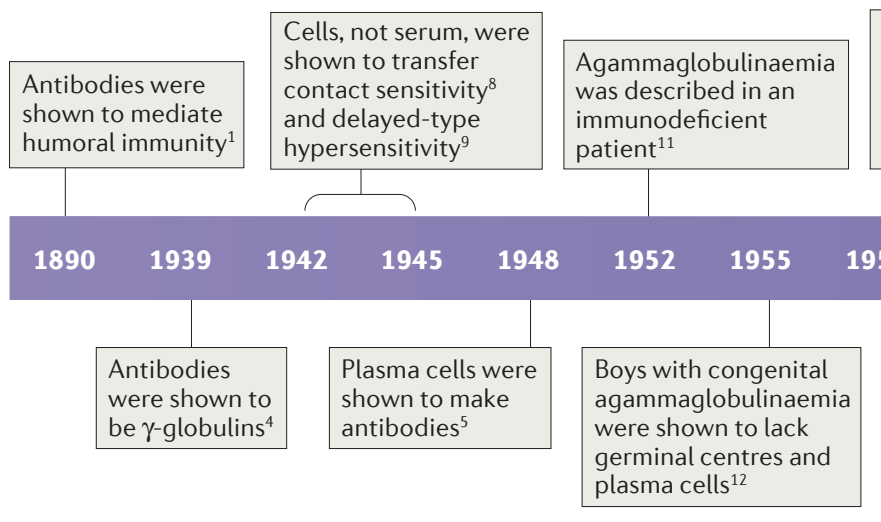

\begin{tabular}{|l|}
\hline Early bursectomy \\
was shown to \\
compromise \\
antibody production \\
in birds ${ }^{13}$
\end{tabular}

Early thymectomy was shown to compromise cellular and humoral immunity in mammals ${ }^{21,22}$
Antibody affinity maturation was defined $^{19}$

Figure 1 | A timeline of the early history of B cells. The timeline shows the discoveries that culminated in the recognition of B cells as a functionally and developmentally distinct lymphocyte lineage in 1965. Early studies also explored the implications of this partition between B cells and T cells, and the dawn of the molecular immunology era in 1976 revealed the genetic basis for B cell receptor diversification and signalling.

light chains connected by disulphide bonds. Their studies also suggested that heavy and light chains have variable and constant regions. Enzymatic cleavage of antibodies by papain yielded a fragment of the heavy chains that could be crystallized because of its homogeneity (known as the fragment crystallizable (Fc)) and a non-homogeneous heavy chain portion that remained attached to the light chains and retained antigenbinding capacity (known as the fragment antigen binding (Fab)). The implications of the variable fragment (Fab) for antibody specificity were immediately evident but an appreciation of the effector functions of the Fc would not come until much later.

Around the same time that these structural insights into antibodies were gained, Frank Macfarlane Burnet ${ }^{16}$ proposed the idea of a clonally diverse repertoire of antibodyproducing cells in which each cell makes one type of antibody and is stimulated by its cognate antigen to produce and secrete more of the same type of antibody. The 'clonal selection' theory of antibody production soon replaced the instructional theory and has endured, with various modifications and interpretations, as a guiding principle of adaptive immunity. The central question then concerned the genetic basis of clonal diversity. Could each cell commit to making a particular antibody by selecting one set of heavy and light chain genes from a huge repertoire or could a limited number of genes be somatically diversified?

When amino acid sequencing became possible, Norbert Hilschmann and Lyman Craig ${ }^{17}$ described sequence variations between the light chains secreted by myeloma cells in different patients. William Dryer and Claude Bennett ${ }^{18}$ then proposed in 1965 the idea of separate light chain variable and constant region genes and hypothesized that one of many variable region genes could be joined with a constant region gene to make a specific antibody heavy or light chain. Recognition of the affinity maturation of antibodies during immune responses added further complexity to the antibody diversification puzzle ${ }^{19}$. In 1970, Martin Weigert and co-workers ${ }^{20}$ discovered that the variable region sequence of the light chain can be somatically diversified and this fuelled a long-lasting debate over the contribution of germline versus somatic antibody diversity.

\section{The thymus in immune system development} In the early 1960s, the attention of immunologists was drawn to the cellular aspects of immunity when the thymus - a lymphoid organ with previously unknown function was discovered to be essential for immune system development. To study why thymectomy inhibits lymphoma development in mice, Jacques Miller ${ }^{21}$ removed the thymus shortly after birth. The thymectomized mice initially did well, but shortly after weaning they developed diarrhoea, runting and fatal infections. This aborted his experimental plan but led Miller to discover that early thymectomy results in a severe immunodeficiency characterized by marked lymphopenia, inability to reject skin allografts and reduced antibody responses ${ }^{21}$. Good and co-workers $^{22}$ followed different clues to discover the importance of the thymus in immune system development. Noting the association between acquired agammaglobulinaemia and a thymoma in an adult patient, they thymectomized rabbits only to find no effect on antibody production. However, after learning that early removal of the avian bursa of Fabricius impaired the development of antibody responsiveness, they found that thymectomy of newborn mice and rabbits inhibited lymphocyte development and both cellular and humoral immune responses ${ }^{22}$. Branislav Jankovic and co-workers ${ }^{23}$ found that thymectomy of neonatal rats had similar immunological consequences.

Subsequent studies suggested that the thymus could function by seeding lymphocytes or by the hormonal control of lymphocyte development elsewhere. In support of the idea that the thymus seeds lymphocytes, thymocyte infusion rescued the lymphocyte deficiency and immune dysfunction of thymectomized mice ${ }^{24}$. James Gowans traced the circular migration of radiolabelled lymphocytes from the bloodstream into the lymph nodes and their exit via the lymphatic channels to re-enter the bloodstream ${ }^{25}$; he also noted that lymphocytes could differentiate into plasma cells ${ }^{26}$. In addition, the primarily epithelial thymus from embryonic mice was shown to produce lymphocytes ex vivo ${ }^{27}$. The composite picture derived from these findings suggested a lymphocyte lineage model in which thymic epithelial cells give rise to lymphocytes that migrate via the circulation to populate secondary lymphoid tissues throughout the body, where they become antibody-producing plasma cells in response to antigen stimulation (FIG. 2a). 
B cells and T cells were shown to cooperate in the antibody response (reviewed in REF. 41)

B cells were shown to originate from the fetal liver and bone marrow in mice ${ }^{51,52,53}$
Pre-B cells were identified ${ }^{55}$

Somatic rearrangement of antibody light chain $\mathrm{V}$ and $\mathrm{C}$ region genes was discovered ${ }^{59}$
B cell receptor $\lg \alpha$ and $\lg \beta$ signalling components were identified (reviewed in REF. 82)

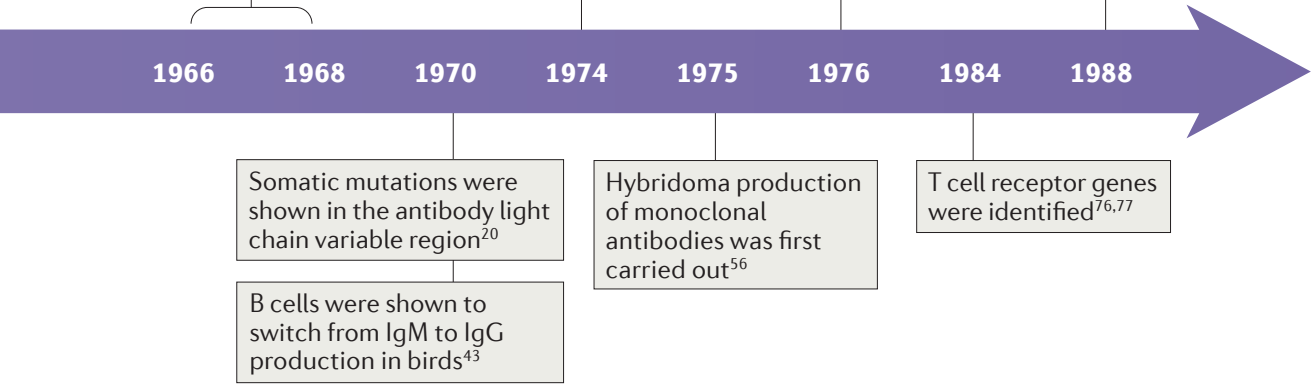

\section{One or more lymphocyte lineage?}

However, this single-lineage model of thymus-derived lymphocytes did not fit well with several observations in birds and patients with immunodeficiency diseases. Testosterone treatment of chick embryos was found to inhibit bursal development and antibody production even more markedly than removal of the bursa at hatching. Noting that in ovo treatment with testosterone sometimes impaired thymus development and the ability to reject allografts, Alexander Szenberg and Noel Warner ${ }^{28}$ suggested in 1962 that the thymus and the bursa have different functions. Their results suggested a model in which the thymus controls allograft rejection, the bursa controls antibody production and delayedtype hypersensitivity, and the bone marrow is responsible for graft-versus-host reactivity ${ }^{29}$. Raymond Peterson and co-workers ${ }^{30}$ found that bursectomy prevented the development of virus-induced lymphomas, whereas thymectomy had no effect. Boys with Wiskott-Aldrich syndrome - which is characterized by recurrent infections, thrombocytopenia and eczema - were noted to have a marked deficiency of lymphocytes and a fatal outcome of herpes simplex virus infection, despite having an abundance of plasma cells and circulating immunoglobulins ${ }^{31}$. Although none of these observations disproved the single-lymphocyte lineage model, they could be more easily explained by the existence of more than one lymphocyte lineage.

\section{Discrete thymus and bursal cell lineages}

Chickens offered an animal model in which to test the possibility of alternative lymphocyte lineages, although it was unclear at the time whether the thymus and the bursa had synergistic or independent roles and just how they might function. It proved difficult to show that early thymectomy affected either cellular or humoral immunity, probably because of the fairly mature status of the immune system in newly hatched chicks. Defining the respective roles of the thymus and the bursa would thus require either removing one or the other early in embryonic life or removing them after hatching in conjunction with the destruction of cells that had developed earlier under their influence. Lacking the means to selectively ablate the embryonic thymus, we decided to combine whole-body irradiation with removal of the thymus and/or the bursa (or neither) immediately after hatching. When examined as young adults, the birds that were irradiated and thymectomized at hatching resembled neonatally thymectomized mice. They were lymphopenic and had severely impaired cell-mediated immunity, as indicated by deficiencies in delayed-type hypersensitivity, graft-versus-host reactivity and allograft rejection capability; antibody responses to some antigens were also reduced even though immunoglobulin production and the development of germinal centres and of plasma cells seemed to be normal ${ }^{7,32}$. Conversely, birds that were irradiated and bursectomized at hatching resembled boys with X-linked agammaglobulinaemia, in that they had no germinal centres or plasma cells and made no antibodies, despite having an abundance of lymphocytes and normal cell-mediated immune responses ${ }^{7,32}$. Notably, germinal centre and plasma cell development could be restored in irradiated and bursectomized birds by reinfusion of their bursal cells ${ }^{33}$. Irradiated, bursectomized and thymectomized birds resembled infection-prone infants who had congenital agammaglobulinaemia, no lymphocytes and deficient cell-mediated and humoral immune responses ${ }^{34,35}$. These composite findings 50 years ago offered a clear view of separate thymus-dependent and bursa-dependent lineages of lymphocytes that mediate cellular and humoral immunity, respectively (FIG. 2b). Compelling evidence for a thymus-independent lineage of lymphocytes in humans was soon provided by Angelo DiGeorge's description ${ }^{36}$ of congenitally athymic infants who had an abundance of plasma cells and antibodies, despite their absence of lymphocytemediated cellular immunity. The existence of haematopoietic progenitor cells for the two lymphocyte lineages was implied by the earlier finding of bone marrow stem cells with multilineage potential ${ }^{37}$, including the potential for thymocyte differentiation ${ }^{38}$, and this idea was validated in chick parabiosis experiments ${ }^{39}$.

Implications of B cell and T cell lineages The recognition of separate differentiation pathways for bursa-dependent and thymusdependent lymphocytes, later termed $\mathrm{B}$ cells and $\mathrm{T}$ cells ${ }^{40}$, provided a provisional map of immune system development. The $B$ cell and $T$ cell lineage model immediately provided a useful outline for analysing the pathogenesis of lymphoid malignancies and immunodeficiency diseases, but it also raised many basic questions. What is the source of B cells in mammals? If B cells use their antibodies as antigen receptors, what do $T$ cells use to recognize antigens given their inability to make antibodies? How do T cells cooperate with B cells to facilitate antibody responses? A discussion of T cells is outside the scope of this Timeline article but these questions and others have led to many other branches of immunological research. The specific issue of collaboration between $\mathrm{B}$ cells and $\mathrm{T}$ cells is addressed in another Timeline article in this Focus issue by Shane Crotty ${ }^{41}$.

\section{Early B cell development}

The prototypic antibodies used in the structural studies of Edelman and Porter in the $1950 \mathrm{~s}^{14,15}$ were IgG antibodies and the identification of different classes of antibodies raised additional questions about the antibody diversification process. By the late 1960s, many immunologists 
a Early 1960s: single-lymphocyte lineage model

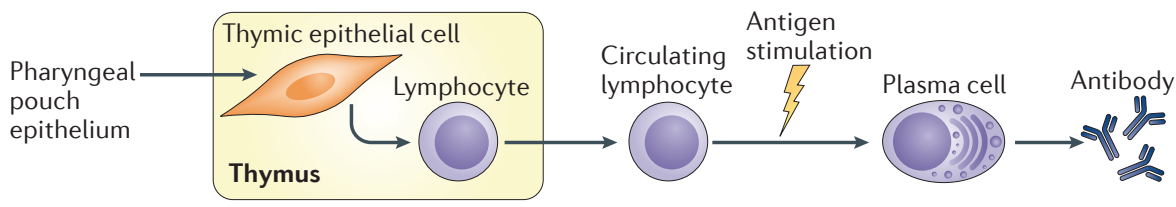

b 1965: two-lymphocyte lineage model

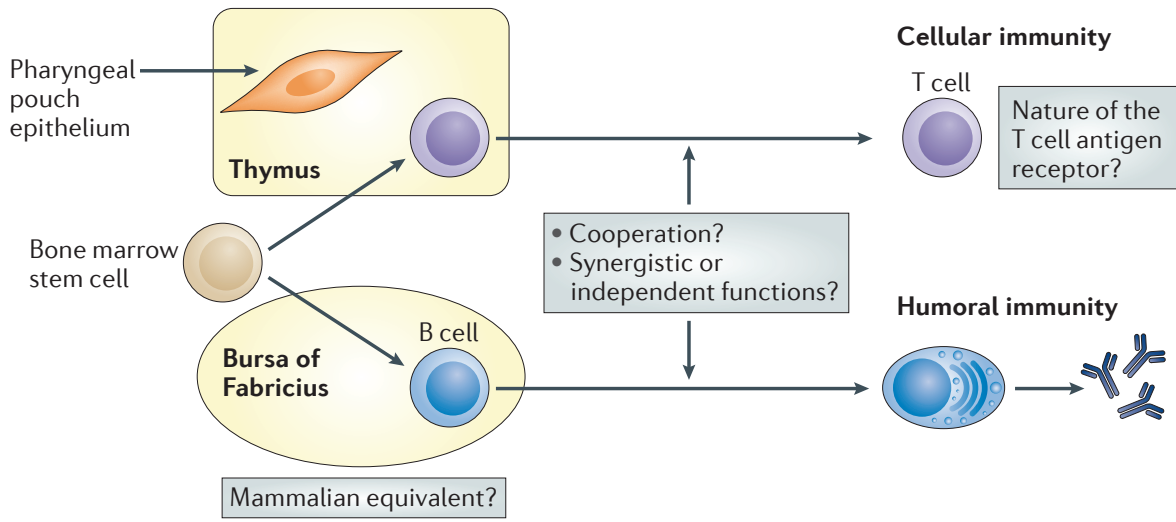

Figure 2 | Schematic illustration of single-lymphocyte versus two-lymphocyte lineage models. a|The single-lymphocyte lineage model. b|The two-lymphocyte lineage model. Grey boxes indicate some of the immediate issues that were raised by the recognition of separate thymus-derived and bursa-derived lymphocyte lineages.

had shown that IgM antibodies are produced before IgG antibodies in antigeninduced responses and during ontogeny. We showed that bursectomy of chickens at different times during development interrupted this progression ${ }^{42}$. These results could be explained either by there being separate lineages of B cells committed to making either IgM or IgG antibodies, or by the capacity of a single lineage of B cells to switch from IgM to IgG production. In favour of the possibility that a single lineage of B cells switches from IgM to IgG production, embryonic treatment with IgM-specific antibodies prevented the development of IgG-producing cells, whereas the inhibitory effects of antibodies against IgG were class specific ${ }^{43}$. Treatment with IgM-specific antibodies also inhibited the development of IgGand IgA-producing cells in mice, but only when antibody administration was initiated at birth and not a week later ${ }^{44}$. These findings suggested that $\operatorname{IgM}^{+} \mathrm{B}$ cells give rise to $\mathrm{B}$ cells that produce other immunoglobulin classes, although the class-switch mechanism was not elucidated until the advent of recombinant DNA technology in the 1980s (see below). How the IgMspecific antibodies inhibited the immature B cells was also unknown at that time, although immunoglobulin expression on lymphocytes had been noted by Goran Moller ${ }^{45}$ in an immunofluorescence study of histocompatibility antigen expression in 1961. Differential expression of cellsurface immunoglobulin or THY1 (also known as CD90) by B cells and T cells, respectively, was shown in mice in 1970 (REF. 46) and the next year, the cell-surface expression of immunoglobulins was shown to be restricted to B cells in chickens and humans ${ }^{47-49}$.

B cell generation in haematopoietic tissues In order to study early events in B cell differentiation, it was essential to determine the site(s) in which B cells are generated in mammals. The gut-associated lymphoid tissues, Peyer's patches and the appendix were early bursa-equivalent candidates and their removal in rabbits, together with whole-body irradiation, selectively compromised humoral immunity ${ }^{50}$. However, B cell development in fetal lambs was not impaired by prior removal of the entire intestine. The generation of $B$ cells in mouse haematopoietic tissues was then convincingly shown by ex vivo analysis of fetal liver development ${ }^{51}$ and by the finding that immunoglobulinbearing lymphocytes were derived from immunoglobulin-negative lymphocytes in adult bone marrow ${ }^{52,53}$ and also in fetal bone marrow ${ }^{54}$. Newly formed B cells are extremely sensitive to IgM-specific antibodies, which abolish these cells in fetal liver cultures; nevertheless, cells with lymphocyte morphology were still present in these cultures. These residual lymphocytes were found to contain intracellular IgM ${ }^{55}$ and DNA-labelling studies were used to trace the developmental sequence of IgM-negative progenitor cells (pro-B cells) to large intracellular IgM-positive precursor cells (pre-B cells) and then to IgM-bearing B cells ${ }^{54}$.

The revolutionary technique of fusing a malignant plasma cell with a normal $\mathrm{B}$ cell to form a hybridoma that produces monoclonal antibodies was discovered during this fertile period of B cell study in the $1970 \mathrm{~s}^{56}$. When pre-B cells in mouse fetal liver were fused with a mutant B cell line that no longer produced immunoglobulin heavy or light chains, hybridomas were generated that only produced $\mu$-heavy chains ${ }^{57}$. This suggested the sequential expression of immunoglobulin heavy then light chains during B cell differentiation, a finding that was later confirmed in virustransformed cell lines that could undergo this differentiation process ${ }^{58}$.

\section{Antibody genes and their assembly}

The advent of recombinant DNA technology provided a powerful new approach to address many of the unresolved issues of B cell differentiation and antibody diversification. The molecular immunology era began in 1976 with the finding by Nobumichi Hozumi and Susumu Tonagawa ${ }^{59}$ that immunoglobulin light chain variable and constant region gene segments undergo somatic rearrangement during B cell differentiation. It was then shown that creation of the light chain variable region exon involves rearrangement of two gene segments $-\mathrm{V}$ (variable) and J (joining) - and that this same process at the heavy chain locus involves three gene segments (V, D (diversity) and J) ${ }^{60,61}$. Recombination signal sequences flanking the V, D and J gene segments were shown to guide the assembly process ${ }^{62,59}$. The sequential recombinatorial assembly of the heavy chain gene first and then the light chain gene can explain the orderly expression of $\mu$-heavy chains by pre-B cells and the subsequent expression of IgM by newly formed B cells ${ }^{58}$. The switch from transmembrane IgM receptors on B cells to secreted IgM antibodies was found to 


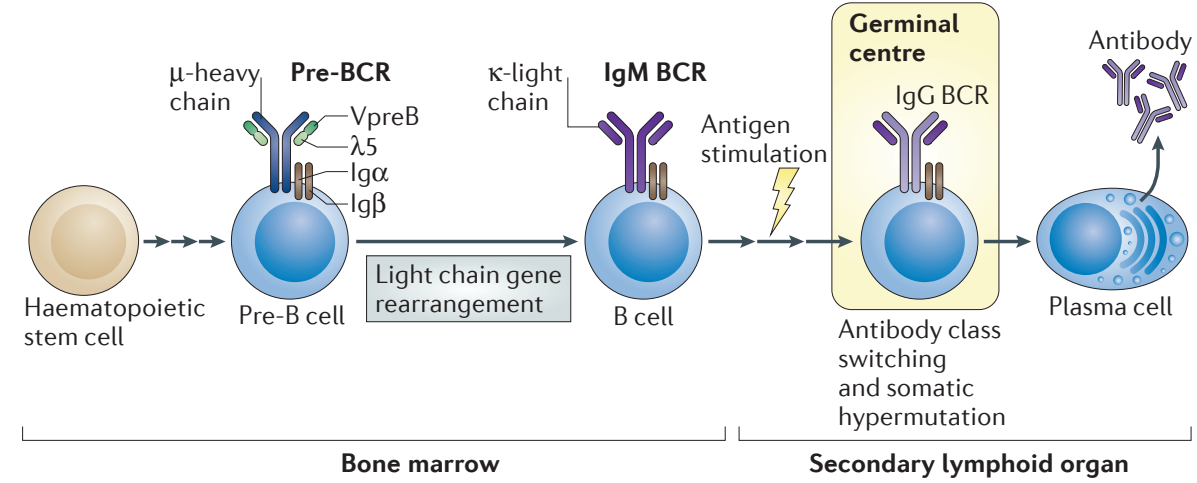

Figure 3 | The composition and the expression of pre-B cell and B cell receptors. The elucidation of the antibody genes and the differential splicing of the heavy chain transcripts provided insight into the transmembrane expression of IgM and $\operatorname{lgD}$ (not shown here) as B cell receptors (BCRs) for antigen recognition on B cells. Pre-B cells, which have not yet rearranged their light chain genes, instead express surrogate light chain genes that encode $\lambda 5$ and $V p r e B$, in combination with the $\mu$-heavy chain ${ }^{83}$. For both the pre-BCR and the BCR, the short intracytoplasmic portions of the $\mu$-heavy chains are inadequate for initiation of signal transduction. The solution to this problem came with the identification of the associated transmembrane proteins $\lg \alpha$ and $\lg \beta$, which have cytoplasmic motifs that undergo phosphorylation after antigen engagement of the receptor complex to trigger the signalling cascades that are responsible for activation of normal and abnormal B cells (reviewed in REFS 82,84,85). be due to alternative splicing of the heavy chain gene transcripts ${ }^{62}$. Antibody class switching was shown to involve deletion of the constant region gene segment of the $\mu$-heavy chain and its replacement by one of the other downstream constant region gene segment ${ }^{63-65}$. The antigen-selected evolution of cumulative somatic mutations proved to be the underlying mechanism for affinity maturation of antibodies ${ }^{66}$ and this process was shown to occur primarily in the germinal centres ${ }^{67}$.

These studies provided insight into the genetic basis for the orderly expression of clonally diverse IgM heavy and then light chain genes, the subsequent switches in constant region genes to enable $\mathrm{B}$ cells to express different antibody classes and the concomitant antigen-mediated selection of somatic mutations (reviewed in REF. 68). However, several more years of research were required to define the composition of the BCR for antigens and that of the preBCR (FIG. 3) as essential first steps in understanding the signalling pathways that are triggered by antigen activation of $B$ cells, the analysis of which is still ongoing.

Many other important discoveries deserve mention in this brief historical sketch of B cells. One is the discovery of the paired recombination-activating gene 1 (RAG1) and RAG2, which encode enzymes that are essential for initiating $\mathrm{V}(\mathrm{D}) \mathrm{J}$ recombination ${ }^{69,70}$. Another is the discovery which encodes an enzyme that is essential of the activation-induced deaminase gene, for initiating heavy chain class switching and somatic mutation of $\mathrm{V}$ regions to promote the affinity maturation of antibodies ${ }^{71}$. Moreover, the gene conversion mechanism that was shown to be essential for generating antibody diversity in the avian bursa of Fabricius ${ }^{72,73}$ is also mediated by this enzyme ${ }^{74}$. With regard to the question of how $\mathrm{T}$ cells 'see' antigens, the discovery that cytotoxic $\mathrm{T}$ cells kill virus-infected cells only in the context of self-MHC class I molecules provided pivotal insight into this issue $^{75}$. The subsequent identification of the $\mathrm{T}$ cell receptor (TCR) genes ${ }^{76,77}$ paved the way to understanding how the MHC class I and class II proteins present peptides to $\mathrm{T}$ cells. Investigations of the two major $T$ cell developmental pathways, in which lymphocytes express either a $\gamma \delta$ TCR or an $\alpha \beta$ TCR, and their many sublineages are ongoing.

\section{Conclusions}

Much has been learnt about the thymusderived $\mathrm{T}$ cells and the bursa- or bone marrow-derived B cells since their recognition as members of separate pathways of lymphocyte differentiation in birds and mammals 50 years ago. This Timeline article concentrates on the early findings that led to the recognition of $\mathrm{B}$ cells as a distinct lymphocyte lineage and the initial investigation of the $B$ cell differentiation pathway. The ongoing analysis of $B$ cells inevitably involves the study of $\mathrm{T}$ cells because they belong to functionally intertwined lymphocyte lineages. In fact, we now know that the genetic programmes for the two major prototypic $\mathrm{T}$ cell lineages and a prototypic $B$ cell lineage must have been present in a common vertebrate ancestor approximately 500 million years ago, even before the convergent evolution of entirely different types of clonally diverse receptors for specific antigens on $B$ cells and $T$ cells in jawless and jawed vertebrates (BOX 1). The reasons why B cells and two types of

\section{Box $1 \mid$ B cell and $T$ cell lineages are ancient}

Although our appreciation of the B cell and T cell pathways of lymphocyte development is fairly recent, this organizational scheme has proven to be a fundamental principle of the adaptive immune system in all vertebrates. All jawed vertebrates, including sharks and other cartilaginous fish, have genes encoding the B cell receptor (BCR), $\gamma \delta$ and $\alpha \beta$ T cell receptors (TCRs), MHC class I and II proteins, and recombination-activating gene 1 protein (RAG1) and RAG2 (REF. 78). An alternative adaptive immune system has been defined in the extant jawless vertebrates, lamprey and hagfish, which have none of the above cardinal elements used by jawed vertebrates to generate clonally diverse receptors for B cells and T cells ${ }^{79}$. Instead of the immunoglobulin-based components that are used by lymphocytes in jawed vertebrates to construct the BCR and the TCR, lymphocytes in the jawless vertebrates use leucine-rich repeat (LRR) sequences to construct variable lymphocyte receptors (VLRs) for antigen recognition (reviewed in REF. 80). Three lamprey VLR loci - VLRA, VLRB and VLRC - each contain an incomplete germline gene that is flanked by hundreds of different LRR-encoding sequences. During their development in a thymus-equivalent or haematopoietic region, lymphocytes use the flanking LRR sequences as templates to assemble mature VLR genes in a stepwise manner. The different VLR types are expressed in a clonally diverse manner by separate lymphocyte lineages. The lamprey VLRA ${ }^{+}$and $V L R C^{+}$lymphocytes resemble thymus-derived $\gamma \delta$ and $\alpha \beta T$ cells, respectively, and $V_{L R B}+$ lymphocytes closely resemble mammalian B cells and give rise to plasma cells that secrete VLRB antibodies ${ }^{81}$. The remarkable parallels between these lymphocyte lineages in jawless and jawed vertebrates suggest that the genetic programmes for the major lymphocyte differentiation pathways evolved in a common ancestor before the convergent evolution of the different types of antigen receptors in jawless and jawed vertebrates. 
T cells have been inseparable companions for so long remain speculative but it seems likely that essential cooperative interactions between $\mathrm{B}$ cells and $\mathrm{T}$ cells underlie their selection for continual evolution of the adaptive immune system in vertebrates.

Max D. Cooper is at the Emory University School of Medicine, 1462 Clifton Road, Atlanta, Georgia 303022, USA.

e-mail: mdcoope@emory.edu doi:10.1038/nri3801 Published online 6 February 2015

1. von Behring, E. \& Kitasato, S. Ueber das zutandekommen der diphtherie-immunitat und der tetanus-immunitat bei thieren. Deutsche Medizinsche Wochenschrift 16, 1113-1114 (1890).

2. Ehrlich, P. Nobel Lecture, December 11, 1908. Nobel lectures, Physiology or Medicine, 1901-1921 (Elsevier, 1967).

3. Haurowitz, F. Immunochemistry. Annu. Rev. Biochem 29, 609-634 (1960).

4. Tiselius, A. \& Kabat, E. A. An electrophoretic study of immune sera and purified antibody preparations. J. Exp. Med. 69, 119-131 (1939).

5. Fagraeus, A. The plasma cellular reaction and its relation to the formation of antibodies in vitro. J. Immunol. 58, 1-13 (1948).

6. Coons, A. H., Leduc, E. H. \& Connolly, J. M. Studies on antibody production. I. A method for the histochemical demonstration of specific antibody and its application to a study of the hyperimmune rabbit. J. Exp. Med. 102, 49-60 (1955).

7 Cooper, M. D., Peterson, R. D. \& Good, R. A. Delineation of the thymic and bursal lymphoid systems in the chicken. Nature 205, 143-146 (1965).

8. Landsteiner $\mathrm{K}$ \& Chase M. W. Experiments on transfer of cutaneous sensitivity to simple compounds. P. Soc. Exp. Biol. Med. 49, 688-690 (1942)

9. Chase, M. W. The cellular transfer of cutaneous hypersensitivity to tuberculin. P. Soc. Exp. Biol. Med. 59, 134-135 (1945)

10. Mechnikov, I. Nobel lecture, December 11, 1908. Nobel lectures, Physiology or Medicine, 1901-1921 (Elsevier, 1967).

11. Bruton, O. C. Agammaglobulinemia. Pediatrics. 6. 722-728 (1952).

12. Good, R. A. \& Varco, R. L. A clinical and experimental study of agammaglobulinemia. Lancet 75, 245-271 (1955).

13. Glick, B., Chang, T. S. \& Jaap, R. G. The bursa of fabricius and antibody production. Poultry Science 35 224-225 (1956)

14. Edelman, G. M. Dissociation of gamma-globulin. J. Am. Chem. Soc. 81, 3155-3156 (1959).

15. Porter, R. R. The hydrolysis of rabbit y-globulin and antibodies with crystalline papain. Biochem. J. 73 119-126 (1959).

16. Burnet, F. M. The Clonal Selection Theory of Acquired Immunity. (Vanderbilt Univ. Press, 1959).

17. Hilschmann, N. \& Craig, L. C. Amino acid sequence studies with Bence-Jones proteins. Proc. Natl Acad. Sci. USA 53, 1403-1409 (1965)

18. Dreyer, W. J. \& Bennett, J. C. The molecular basis of antibody formation: a paradox. Proc. Natl Acad. Sci. USA 54, 864-869 (1965).

19. Eisen, H. N. \& Siskind, G. W. Variations in affinities of antibodies during the immune Response. Biochemistry 3, 996-1008 (1964)

20. Weigert, M. G., Cesari, I. M., Yonkovich, S. J. \& Cohn, M. Variability in the lambda light chain sequences of mouse antibody. Nature 228 1045-1047 (1970).

21. Miller, J. F. Immunological function of the thymus Lancet 2, 748-749 (1961).

22. Good, R. A. et al. The role of the thymus in development of immunologic capacity in rabbits and mice. J. Exp. Med. 116, 773-796 (1962).

23. Jankovic, B. D., Waksman, B. H. \& Arnason, B. G Role of the thymus in immune reactions in rats. I. The immunologic response to bovine serum albumin (antibody formation, arthus reactivity, and delayed hypersensitivity) in rats thymectomized or splenectomized at various times after birth

J. Exp. Med. 116, 159-176 (1962)

24. Hilgard, H. R., Yunis, E. J., Sjodin, K., Martinez, C. $\delta$ Good, R. A. Reversal of wasting in thymectomized mice by the injection of syngeneic spleen or thymus cell suspensions. Nature 202, 668-670 (1964).

25. Gowans, J. L. \& Knight, E. J. The route of re-circulation of lymphocytes in the rat. Proc. R. Soc. B. Biol. Sci. 159, 257-282 (1964)

26. Gowans, J. L. \& McGregor, D. D. The Origins of Antibody-Forming Cells. Immunopathology: IIIrd International Symposium (eds Grabar, P. \& Miescher, P. A.) 89 (Schwabe, 1963)

27. Auerbach, R. Experimental analysis of the origin of cell types in the development of the mouse thymus. Dev. Biol. 3, 336-354 (1961)

28. Szenberg, A. \& Warner, N. L. Dissociation of immunological responsiveness in fowls with a hormonally arrested development of lymphoid tissues. Nature 194, 146-147 (1962).

29. Warner, N. L., Szenberg, A. \& Burnet, F. M The immunological role of different lymphoid organs in the chicken. I. Dissociation of immunological responsiveness. Austral. J. Exp. Biol. Med. Sci. 40, 373-387 (1962)

30. Peterson, R. D., Burmester, B. R., Frederick, T. N., Purchase, H. G. \& Good, R. A. Effect of bursectomy and thymectomy on development of visceral lymphomatosis in chicken. J. Natl Cancer Inst. 32 1343-1353 (1964).

31. Cooper, M. D., Chae, H. P., Lowman, J. T., Krivit, W. \& Good, R. A. Wiskott-Aldrich syndrome. An immunologic deficiency disease involving the afferent limb of immunity. Am. J. Med. 44 499-513 (1968)

32. Cooper M. D Raymond, D. A Peterson, R. D., South, M. A. \& Good, R. A. The functions of the thymus system and the bursa system in the chicken. J. Exp. Med. 123, 75-102 (1966).

33. Cooper, M. D. Schwartz, M. M. \& Good, R. A. Restoration of $\gamma$-globulin production in agammaglobulinemic chickens. Science 151 , 471-473 (1966)

34. Glanzmann, E. Die essentielle erythroblastopenie mit anamie vom typus Diamond-Blackfan. Experientia $1,118(1945)$

35. Hitzig, W. H., Biro, Z., Bosch, H. \& Huser, H. J. Agammaglobulinemia and alymphocytosis with atrophy of lymphatic tissue. Helvet. Paediatr. Acta 13, 551-585 (1958).

36. DiGeorge, A. M. Congenital absence of the thymus and its immunologic consequences: Concurrence with congenital hypoparathyroidism. Birth Defects Original Article Series 4, 116-121 (1968).

37. Becker, A. J., Mc, C. E. \& Till, J. E. Cytological demonstration of the clonal nature of spleen colonies derived from transplanted mouse marrow cells. Nature 197, 452-454 (1963).

38. Ford, C. E. \& Micklem, H. S. The thymus and lymphnodes in radiation chimaeras. Lancet 1, 359-362 (1963)

39. Moore, M. A. S. \& Owen, J. J. T. Stem-cell migration in developing myeloid and lymphoid systems. Lancet 2 , 658-659 (1967).

40. Roitt, I. M., Greaves, M. F., Torrigiani, G., Brostoff, J. \& Playfair, J. H. The cellular basis of immunological responses. A synthesis of some current views. Lancet 2, 367-371 (1969).

41. Crotty, S. A brief history of T cell help to B cells. Nature Rev. Immunol. 15, 185-189 (2015).

42. Cooper, M. D. Cain, W. A Van Alten, P. J. \& Good, R. A. Development and function of the immunoglobulin producing system. I. Effect of bursectomy at different stages of development on germinal centers, plasma cells, immunoglobulins and antibody production. Int. Arch. Allergy Appl. Immunol. 35, 242-252 (1969).

43. Kincade, P. W., Lawton, A. R., Bockman, D. E. \& Cooper, M. D. Suppression of immunoglobulin C synthesis as a result of antibody-mediated suppression of immunoglobulin M synthesis in chickens. Proc. Natl Acad. Sci. USA 67, 1918-1925 (1970)

44. Lawton, A. R., Asofsky, R., Hylton, M. B. \& Cooper, M. D. Suppression of immunoglobulin class synthesis in mice. I. Effects of treatment with antibody to $\mu$-chain. J. Exp. Med. 135, 277-297 (1972)

45. Moller, G. Demonstration of mouse isoantigens at the cellular-level by the fluorescent-antibody technique. J. Exp. Med. 114, 415-434 (1961).
46. Raff, M. C., Sternber, M. \& Taylor, R. B. Immunoglobulin determinants on surface of mouse lymphoid cells. Nature 225, 553-554 (1970)

47. Rabellino, E. \& Grey, H. M. Immunoglobulins on the surface of lymphocytes. 3. Bursal origin of surface immunoglobulins on chicken lymphocytes. J. Immunol. 106, 1418-1420 (1971).

48. Kincade, P. W., Lawton, A. R. \& Cooper, M. D Restriction of surface immunoglobulin determinants to lymphocytes of the plasma cell line. J. Immunol. 106, 1421-1423 (1971)

49. Cooper, M. D., Lawton, A. R. \& Bockman, D. E. Agammaglobulinaemia with B lymphocytes: A specific defect of plasma cell differentiation Lancet 2, 791-795 (1971).

50. Cooper, M. D. et al. A mammalian equivalent of the avian bursa of Fabricius. Lancet 1, 1388-1391 (1966)

51. Owen, J. J., Cooper, M. D. \& Raff, M. C. In vitro generation of $\mathrm{B}$ lymphocytes in mouse foetal liver, a mammalian 'bursa equivalent'. Nature 249, 361-363 (1974).

52. Osmond, D. G. \& Nossal, G. J. Differentiation of lymphocytes in mouse bone marrow. II. Kinetics of maturation and renewal of antiglobulin-binding cells studied by double labeling. Cellular Immunology 13, 132-145 (1974).

53. Ryser, J. E. \& Vassalli, P. Mouse bone marrow lymphocytes and their differentiation. J. Immunol. 113, 719-728 (1974).

54. Owen, J. J., Raff, M. C. \& Cooper, M. D. Studies on the generation of $B$ lymphocytes in the mouse embryo. Eur. J. Immunol. 3, 468-473 (1975).

55. Raff, M. C., Megson, M., Owen, J. J. \& Cooper, M. D. Early production of intracellular IgM by B-lymphocyte precursors in mouse. Nature 259 224-226 (1976).

56. Kohler, G. \& Milstein, C. Continuous cultures of fused cells secreting antibody of predefined specificity. Nature 256, 495-497 (1975).

57. Burrows, P., LeJeune, M. \& Kearney, J. F. Evidence that murine pre-B cells synthesise $\mu$-heavy chains but no light chains. Nature 280, 838-840 (1979).

58. Alt, F. W. et al. Ordered rearrangement of immunoglobulin heavy chain variable region segments. EMBO J. 3, 1209-1219 (1984).

59. Hozumi, N. \& Tonegawa, S. Evidence for somatic rearrangement of immunoglobulin genes coding for variable and constant regions. Proc. Natl Acad. Sci. USA 73, 3628-3632 (1976).

60. Bernard, O., Hozumi, N. \& Tonegawa, S. Sequences of mouse immunoglobulin light chain genes before and after somatic changes. Cell 15, 1133-1144 (1978).

61. Early, P., Huang, H., Davis, M., Calame, K. \& Hood, L. An immunoglobulin heavy chain variable region gene is generated from three segments of DNA: VH, D and JH. Cell 19, 981-992 (1980).

62. Rogers, J. et al. Two mRNAs with different 3 ends encode membrane-bound and secreted forms of immunoglobulin $\mu$-chain. Cell 20, 303-312 (1980)

63. Davis, M. M. et al. An immunoglobulin heavy-chain gene is formed by at least two recombinational events. Nature 283, 733-739 (1980).

64. Sakano, H., Maki, R., Kurosawa, Y., Roeder, W. \& Tonegawa, S. Two types of somatic recombination are necessary for the generation of complete immunoglobulin heavy-chain genes. Nature 286, 676-683 (1980).

65. Yaoita, Y. \& Honjo, T. Deletion of immunoglobulin heavy chain genes from expressed allelic chromosome. Nature 286, 850-853 (1980).

66. McKean, D. et al. Generation of antibody diversity in the immune response of $\mathrm{BALB} / \mathrm{c}$ mice to influenza virus hemagglutinin. Proc. Natl Acad. Sci. USA 81 3180-3184 (1984)

67. Jacob, J., Kelsoe, G., Rajewsky, K. \& Weiss, U. Intraclonal generation of antibody mutants in germinal centres. Nature 354, 389-392 (1991).

68. Kocks, C. \& Rajewsky, K. Stable expression and somatic hypermutation of antibody $\mathrm{V}$ regions in $\mathrm{B}$-cell developmental pathways. Annu. Rev. Immunol. 7, 537-559 (1989).

69. Schatz, D. G., Oettinger, M. A. \& Baltimore, D The V(D)J recombination activating gene, RAG-1. Cell 59, 1035-1048 (1989).

70. Oettinger, M. A., Schatz, D. G., Gorka, C. \& Baltimore, D. RAG-1 and RAG-2, adjacent genes that synergistically activate $V(D) J$ recombination. Science 248, 1517-1523 (1990).

71. Muramatsu, M., et al. Class switch recombination and hypermutation require activation-induced cytidine deaminase (AID), a potential RNA editing enzyme. Cell 102, 553-563 (2000). 
72. Reynaud, C. A., Anquez, V., Grimal, H. \& Weill, J. C. A hyperconversion mechanism generates the chicken light chain preimmune repertoire. Cell 48, 379-388 (1987).

73. Thompson, C. B. \& Neiman, P. E. Somatic diversification of the chicken immunoglobulin light chain gene is limited to the rearranged variable gene segment. Cell 48, 369-378 (1987).

74. Di Noia, J. M. \& Neuberger, M. S. Immunoglobulin gene conversion in chicken DT40 cells largely proceeds through an abasic site intermediate generated by excision of the uracil produced by AID-mediated deoxycytidine deamination. Eur. J. Immunol. 34, 504-508 (2004)

75. Zinkernagel, R. M. \& Doherty, P. C. Cytotoxic thymus derived lymphocytes in cerebrospinal fluid of mice with lymphocytic choriomeningitis. J. Exp. Med. 138, 1266-1269 (1973).

76. Yanagi, Y. et al. A human T cell-specific cDNA clone encodes a protein having extensive homology to immunoglobulin chains. Nature $308,145-149$ (1984).

77. Hedrick, S. M., Cohen, D. I., Nielsen, E. A. \& Davis, M. M. Isolation of cDNA clones encoding T cell-specific membrane-associated proteins. Nature 308, 149-153 (1984)

78. Pancer, Z et al. Somatic diversification of variable lymphocyte receptors in the agnathan sea lamprey. Nature 430, 174-180 (2004).

79. Litman, G. W., Rast, J. P. \& Fugmann, S. D. The origins of vertebrate adaptive immunity. Nature Rev. Immunol. 10, 543-553 (2010).

80. Herrin, B. R. \& Cooper, M. D. Alternative adaptive immunity in jawless vertebrates. J. Immunol. 185 1367-1374 (2010).

81. Hirano, M. et al. Evolutionary implications of a third lymphocyte lineage in lampreys. Nature $\mathbf{5 0 1}$ 435-438 (2013).

82. Reth, M. et al. The B-cell antigen receptor complex. Immunol. Today 12, 196-201 (1991).
83. Karasuyama, H., Rolink, A. \& Melchers, F. Surrogate light chain in B cell development. Adv. Immunol. 63, 1-41 (1996).

84. Reth, M. \& Nielsen, P. Signaling circuits in early B-cell development. Adv. Immunol. 122, 129-175 (2014).

85. Avalos, A. M., Meyer-Wentrup, F. \& Ploegh, H. L. $B$-cell receptor signaling in lymphoid malignancies and autoimmunity. Adv. Immunol. 123, 1-49 (2014).

\section{Acknowledgements}

The author greatly appreciates the invaluable support and guidance of his colleagues, research support from the US National Institutes of Health and Georgia Research Alliance, and P. D. Burrows' helpful critique of this historical sketch.

\section{Competing interests statement}

The author declares no competing interests. 